\title{
HIGIENE DAN SANITASI PADA PEDAGANG MAKANAN JAJANAN BALI DI DESTINASI WISATA KULINER PASAR MALAM SINDU, SANUR, BALI
}

\author{
Nelsye Lumanauw \\ Email: nel_sye@ hotmail.com \\ POLITEKNIK INTERNASIONAL BALI
}

\begin{abstract}
Sindu night market as a culinary destination is in good demand by foreign tourists staying in Sanur to enjoy traditional Indonesian foods. Various traditional foods are available in this market, such as Nasi Campur Banyuwangi, Sate-Gule Kambing Madura, including other Balinese food. Traditional Balinese foods have a strong tast, but have not been much sought after by tourists. In-depth research on hygiene and sanitation at Bali food vendors shows a problem and weakness.

This research uses a descriptive method through a cross-sectional approach which allows textual data from interviews to be quantified for clear measurements. Subject measurement was performed on the subject variable at the time of examination. This does not mean that all research subjects were observed at the same time, but can be different subject at different times. The subjects of this study are the characteristics of food traders, personal hygiene of food traders, equipment sanitation and serving sanitation.

The conclusion of this study showed that generally traditional Balinese street food traders at the Sindu night market understand the importance of taking hygiene and sanitation measures for food safety, seen from the characteristics of food traders, personal hygiene of food traders, equipment sanitation and serving sanitation. However, not all traders apply this when providing services.
\end{abstract}

Keywords: Hygiene, Sanitation, Food Handler, Snacks, Culinary Tourism.

\begin{abstract}
Abstrak
Pasar malam Sindu sebagai destinati wisata kuliner sangat diminati wisatawan mancanegara yang menginap di Sanur untuk menikmati makanan tradisional Indonesia. Berbagai makanan tradisional tersedia di pasar ini, seperti nasi campur Banyuwangi, sate-gule kambing Madura, termasuk makanan jajanan Bali. Makanan tradisional Bali memiliki cita rasa kuat, namun belum banyak diminati wisatawan.
\end{abstract}


Penelitian mendalam terhadap higiene sanitasi pada pedagang makanan jajanan Bali menunjukkan suatu kendala dan kelemahan.

Penelitian ini menggunakan metode deskriptif, melalui pendekatan cross-sectional, yang memungkinkan data tekstual hasil wawancara dikuantifikasi untuk pengukuran secara jelas. Pengukuran subyek dilakukan terhadap variabel subyek pada saat pemeriksaan. Hal ini tidak berarti semua subyek penelitian diamati pada waktu yang sama, tetapi bisa lain waktu dengan subyek yang berbeda. Adapun subyek yang menjadi penelitian ini adalah karakteristik pedagang makanan, higiene perorangan pedagang makanan, sanitasi peralatan dan sanitasi penyajian.

Kesimpulan penelitian ini adalah para pedagang makanan jajanan tradisional Bali di pasar malam Sindu, secara umum paham terhadap pentingnya melakukan tindakan higiene dan sanitasi untuk keamanan makanan, dilihat dari karakteristik pedagang makanan, higiene perorangan pedagang makanan, sanitasi peralatan dan sanitasi penyajian. Namun demikian, tidak semua pedagang menerapkan hal tersebut saat memberikan layanan.

Kata Kunci: Higiene, Sanitasi, Penjamah Makanan, Makanan Ringan, Wisata Kuliner.

\section{Pendahuluan}

Industri pariwisata rentan terhadap berbagai isu, salah satunya adalah kesehatan. Wisatawan akan membatalkan kunjungannya apabila terjadi ancaman kesehatan pada destinasi yang akan dikunjungi. Makanan berperan penting dalam menunjang kesehatan.

Salah satu upaya mengantisipasi ancaman kesehatan pada makanan yaitu dengan memperhatikan dan melakukan tindakan higiene sanitasi. Masalah higiene tidak dapat dipisahkan dari masalah sanitasi (Ichwan Prastowo, 2017: 5). Pada saat pengolahan makanan kegiatan sanitasi dan higiene dilaksanakan bersama-sama.

Pengolahan makanan harus memperhatikan kebersihan area, peralatan, higiene perorangan, yang meliputi pengadaan bahan makanan yang berkualitas baik, penerimaan, pencucian, peracikan, pembuatan, pengubahan bentuk, pewadahan, penyimpanan, pengangkutan, hingga 
penyajian makanan atau minuman. Setiap proses tersebut berperan penting terhadap kesuksesan untuk menciptakan keamanan makanan.

Keamanan makanan di Indonesia tertuang pada Undang Undang tentang Pangan RI No. 18 Tahun 2012, tentang Keamanan, Mutu \& Gizi Pangan yang menyebutkan bahwa "Keamanan Pangan adalah kondisi dan upaya yang diperlukan untuk mencegah Pangan dari kemungkinan cemaran biologis, kimia, dan benda lain yang dapat mengganggu, merugikan, dan membahayakan kesehatan manusia serta tidak bertentangan dengan agama, keyakinan, dan budaya masyarakat sehingga aman untuk dikonsumsi”.

Pasar malam Sindu sebagai destinasi wisata kuliner menjadi tempat favorit bagi wisatawan mancanegara, khususnya yang menginap di Sanur. Pengunjung yang sebagian besar wisatawan mancanegara menjadi keunikan tersendiri bagi pasar ini, di samping kebersihan, kerapihan dan keberadaan makanan jajanan dari berbagai daerah di Indonesia. Atas berbagai keunikan tersebut, pasar Sindu telah mendapatkan berbagai penghargaan tingkat nasional dan internasional, seperti: juara pertama sebagai Inovasi Pasar Rakyat dan terbaik dalam pengelolaan pasar kuliner se-Indonesia pada tahun 2017 dan Pasar Terbaik Tingkat Asia tahun 2018, seperti tercantum pada penelitian Lumanauw (2018).

Beragam makanan jajanan dari berbagai daerah di Indonesia terdapat di pasar ini. Makanan jajanan disukai oleh masyarakat, di samping rasanya enak juga memiliki nilai tersendiri karena merupakan salah satu ciri khas dari suatu daerah. Hal ini disampaikan dalam penelitian oleh Setyawanti dan Andayani (2015).

Beragam makanan jajanan tradisional yang dijual di pasar ini, adalah sate gule kambing, nasi campur Banyuwangi, nasi campur Jember, nasi Bali, bakso, soto, jus buah, gorengan, serombotan, tipat cantok, ikan bakar khas Jimbaran. Wisatawan mancanegara berbaur dengan masyarakat 
lokal menikmati makan malam di pasar malam Sindu dengan berbagai pilihan menu yang tersedia.

Makananan jajanan Bali memiliki citarasa yang kuat dan unik. Namun keberadaannya belum mampu bersaing dengan makanan jajanan dari daerah lain di Indonesia, menurut penelitian Lumanauw (2018). Penelitian mendalam terhadap higiene sanitasi pada pedagang makanan jajanan tradisional Bali menunjukkan suatu kendala dan kelemahan.

Pedagang makanan jajanan Bali belum menerapkan tindakan sanitasi dan higiene yang memadai serta kurangnya kesadaran atas pentingnya keamanan makanan. Hal ini tampak pada pelaksanaan saat melakukan penjualan dan pemberian layanan makanan. Tindakan-tindakan higiene dan sanitasi yang tidak dilakukan oleh beberapa pedagang, contohnya: tidak mencuci tangan sebelum menjamah makanan, tidak memakai sarung tangan saat mengambil atau mencampur makanan, tidak memakai celemek, tempat cuci piring hanya satu bak tidak ada tempat bilasan.

Evaluasi terhadap higiene dan sanitasi mencakup pertanyaanpertanyaan, seperti: apakah penjamah makanan melakukan higiene perorangan?, apakah sanitasi peralatan dilakukan?, bagaimanakah sanitasi penyajian makanan?. Jawaban atas pertanyaan-pertanyaan tersebut menggambarkan keadaan higiene dan sanitasi pedagang makanan jajanan Bali di pasar malam Sindu. Dengan demikian dapat ditetapkan perancangan ulang terhadap tindakan higiene dan sanitasi tersebut.

Adanya ketidaksesuaian antara tindakan higiene dan sanitasi yang telah dilakukan dengan kurangnya minat wisatawan mancanegara terhadap makanan tradisional Bali, menunjukkan pentingnya penelitian ini dilakukan.

Berdasarkan latar belakang tersebut, rumusan masalah yang diangkat dari penelitian ini adalah bagaimana penerapan higiene dan 
sanitasi pada pedagang makanan tradisional di Pasar Malam Sindu, Sanur, Bali?. Adapun tujuan penelitian ini untuk mengetahui penerapan higiene dan sanitasi para pedagang makanan tradisional di Pasar Malam Sindu, Sanur, Bali.

\section{Tinjauan Pustaka}

Tinjauan Pustaka penelitian ini akan membahas tentang pengertian higiene, pengertian sanitasi, penjamah makanan, peralatan, makanan jajanan, dan wisata kuliner.

\section{A. Pengertian Higiene}

Higiene merupakan suatu disiplin ilmu yang mempelajari bagaimana hidup sehat dan cara untuk mencapai kondisi higienis (hygiene condition) (Bartono, 2008: 69). Hal ini berlaku untuk makanan, peralatan sehari-hari, ruangan, fasilitas, pakaian, tubuh manusia dan sebagainya. Dengan kata lain, higiene juga berarti suatu pencegahan penyakit yang menitikberatkan pada usaha kesehatan perseorangan atau manusia beserta lingkungan tempat orang tersebut berada (Widyati dan Yuliarsih, 2002: 14) Tercapainya kondisi higienis menjadikan hidup nyaman, aman pada waktu makan dan bebas bahaya keracunan makanan.

Tindakan-tindakan yang termasuk higiene (Widyati dan Yuliarsih, 2002: 30)

1. Menjaga kebersihan ruangan beserta perabotnya, alat-alat atau perlengkapan makanan dan minuman. Selain makanan dan minuman, perlengkapan untuk makan dan minum, seperti piring, gelas, sendok dan garpu, juga harus dijaga jangan sampai terkontaminasi.

2. Alat-alat yang rusak atau hilang harus segera diperbaiki dan diganti, seperti piring atau gelas yang pecah, panci yang bocor. 
3. Menyediakan fasilitas-fasilitas yang berguna bagi kesehatan: sumber air yang memenuhi syarat kesehatan, pembuangan sampah, dan air limbah.

\section{B. Pengertian Sanitasi}

Sanitasi mengarah pada usaha kongkrit dalam mewujudkan kondisi higienis yang diwujudkan dengan pergerakan di lapangan berupa: pembersihan, penataan, sterilisasi, penyemprotan hama (Bartono, 2008: 70). Suatu usaha pencegahan penyakit yang menitikberatkan kegiatan pada usaha kesehatan lingkungan hidup manusia juga menjadi pengertian dari sanitasi (Widyati dan Yuliarsih, 2002: 14).

Peraturan Menteri Kesehatan Republik Indonesia Nomor 942/MENKES/PER/VII/2003 tentang Pedoman Persyaratan Hygiene Sanitasi Makanan Jajanan, mengemukakan hygiene sanitasi adalah upaya untuk mengendalikan faktor risiko terjadinya kontaminasi terhadap makanan, orang, tempat dan peralatannya yang dapat atau mungkin dapat menimbulkan penyakit atau gangguan kesehatan.

Manfaat dan pentingnya sanitasi (Widyati dan Yuliarsih, 2002: 14)

1. Mencegah penyakit menular

2. Mencegah kecelakaan

3. Mencegah timbulnya bau yang tidak sedap

4. Menghindari pencemaran

5. Mengurangi jumlah (persentase) sakit

6. Lingkungan menjadi bersih, sehat dan nyaman. 


\section{Penjamah Makanan}

Berdasarkan Keputusan Menteri Kesehatan Republik Indonesia Nomor 942/MENKES/SK/VII/2003 tentang Pedoman Persyaratan Hygiene Sanitasi Makanan Jajanan, penjamah makanan jajanan adalah orang yang secara langsung atau tidak langsung berhubungan dengan makanan dan peralatannya sejak dari tahap persiapan, pembersihan, pengolahan, pengangkutan sampai dengan penyajian.

Penjamah makanan dalam melakukan kegiatan pelayanan penanganan makanan harus memenuhi persyaratan antara lain:

a. Tidak menderita penyakit mudah menular, seperti: batuk, pilek, influenza, diare, penyakit perut sejenisnya.

b. Menutup luka (pada luka terbuka/bisul atau luka lainnya).

c. Menjaga kebersihan tangan, rambut, kuku dan pakaian.

d. Memakai celemek dan tutup kepala.

e. Mencuci tangan setiap kali hendak menangani makanan.

f. Menjamah makanan harus memakai alat/perlengkapan atau dengan alas tangan.

g. Tidak sambil merokok, menggaruk anggota badan (telinga, hidung, mulut).

h. Tidak batuk atau bersin di hadapan makanan jajanan yang disajikan dan atau tanpa menutup mulut atau hidung.

\section{Peralatan}

Menurut Keputusan Menteri Kesehatan Republik Indonesia Nomor 942/MENKES/SK/VII/2003 tentang Pedoman Persyaratan Hygiene Sanitasi Makanan Jajanan, peralatan adalah barang yang digunakan untuk penanganan makanan jajanan harus sesuai dengan peruntukannya dan memenuhi persyaratan higiene dan sanitasi. Menjaga peralatan, bisa dengan cara: 
a. Peralatan yang sudah dipakai dicuci dengan air bersih dan dengan sabun.

b. Lalu dikeringkan dengan alat pengering atau lap yang bersih.

c. Kemudian peralatan yang sudah bersih disimpan di tempat yang bebas pencemaran.

d. Dilarang menggunakan kembali peralatan yang dirancang hanya untuk sekali pakai.

\section{E. Makanan Jajanan}

Keputusan Menteri Kesehatan Republik Indonesia Nomor 942/MENKES/SK/VII/2003 tentang Pedoman Persyaratan Hygiene Sanitasi Makanan Jajanan mengemukakan bahwa makanan jajanan adalah makanan dan minuman yang diolah oleh pengrajin makanan di tempat penjualan dan atau disajikan sebagai makanan siap santap untuk dijual bagi umum selain yang disajikan jasa boga, rumah makan/restoran, dan hotel.

\section{F. Wisata Kuliner}

Menurut Simanjuntak dkk (2015: 191), wisata kuliner merupakan perpaduan antara menikmati suatu makanan sambil menikmati suasana jalan-jalan dan bersantai (Simanjuntak et al, 2015: 191).

Wisata kuliner menekankan pada pengalaman gastronomi yang unik dan mengesankan. Bukan suatu hal yang mewah, walaupun sederhana tetapi memberikan kesan lain dari biasanya (Putra, 2017: 138). Gastronomi menekankan pada aktivitas menikmati makanan yang disertai dengan pengalaman dan mempelajari sejarah, budaya dari makanan itu sendiri. 


\section{Metode Penelitian}

Penelitian ini menggunakan metode analisi deskriptif, dengan mengumpukan dan merangkum data untuk mendapatkan gambaran yang jelas, melalui pendekatan cross-sectional. Menurut Malhotra (2009: 101), cross-sectional adalah pengumpulan data atau informasi yang dilakukan satu waktu tertentu, terhadap subyek terpilih diantara keseluruhan populasi. Setiap subyek penelitian diobservasi satu kali pada satu waktu. Pengukuran subyek dilakukan terhadap variabel subyek pada saat pemeriksaan. Hal ini tidak berarti semua subyek penelitian diamati pada waktu yang sama, tetapi bisa lain waktu dengan subyek yang berbeda.

Lokasi penelitian di Pasar Sindu Jalan Sindu No 5, Sanur, Denpasar Selatan, Kota Denpasar, Bali 80288. Pemilihan lokasi tersebut sebagai obyek penelitian dengan pertimbangan berikut:

a. Pasar Sindu, Sanur telah mendapat berbagai penghargaan tingkat nasional maupun internasional.

b. Pengunjung pasar malam Sindu sebagian besar adalah wisatawan mancanegara yang ingin menikmati makanan tradisional Indonesia.

Jenis data pada penelitian ini adalah primer dan sekunder. Data primer diperoleh langsung dari para pedagang makanan jajanan Bali di pasar malam Sindu. Data sekunder diperoleh dari pihak lain berupa dokumen, laporan hasil penelitian, artikel dan buku-buku.

Sumber data primer berupa karakteristik pedagang makanan tradisional yang mencakup umur, jenis kelamin, pendidikan, lama bekerja. Data primer juga berupa higiene perorangan, pedagang makanan jajanan, sanitasi peralatan dan sanitasi penyajian makanan. Adapun sumber data sekunder berupa gambaran umum pasar tradisional Sindu.

Instrumen penelitian diperlukan untuk memperoleh data yang berkualitas. Penelitian ini menggunakan instrumen berupa dokumen, pedoman wawancara dan kamera. Teknik pengumpulan data melalui 
observasi, wawancara mendalam dan studi dokumentasi. Penelitian crosssectional memungkinkan data tekstual hasil wawancara dapat dikuantifikasi untuk pengukuran secara jelas.

\section{Hasil dan Pembahasan}

Di pasar malam Sindu terdapat 32 unit pedagang makanan dari berbagai daerah di Indonesia. Namun hanya 6 warung sebagai pedagang makanan jajanan Bali pada penelitian Lumanauw (2018), yaitu warung Gado-Gado, warung Bali, warung Purnama, warung Jaje Bali, warung Luh De Jimbaran dan warung Gosa.

Penelitian terhadap empat (4) warung pedagang makanan jajanan Bali, yaitu warung Gado-Gado (1 orang), warung Jaje Bali (1 orang), warung Luh De Jimbaran (4 orang) dan warung Gosa (2 orang) dilakukan pada tanggal 15 September 2018. Penelitian terhadap warung makanan jajanan Jaje Bali (2 orang) dan warung minuman jus Purnama (3 orang) dilakukan pada hari Senin, tanggal 17 September 2018. Dengan demikian, keenam unit warung tersebut dijaga oleh 13 orang dan menjadi subyek penelitian ini.

\section{A. Karakteristik Pedagang Makanan}

Karakteristik profil pedagang makanan jajanan di pasar malam Sindu ditinjau dari golongan usia, jenis kelamin, lamanya berjualan dan tingkat pendidikan terakhir. Aspek-aspek tersebut digunakan untuk mendukung dalam mengetahui pengaruh tindakan higiene sanitasi yang dilakukan pedagang.

Karakteristik pedagang makanan jajanan Bali di pasar malam Sindu berdasarkan hasil penelitian disajikan pada Tabel 1. 


\section{Tabel 1}

Distribusi Karakteristik Pedagang Makanan

Di Pasar Malam Sindu, Sanur, Bali

\begin{tabular}{clrr}
\hline No & \multicolumn{1}{c}{ Karakteristik } & Jumlah & $\%$ \\
\hline 1 & Golongan usia : & & \\
& a. $<24$ tahun & 0 & 0 \\
& b. $24-54$ tahun & 12 & 92 \\
& c. $\geq 55$ tahun & 1 & 8 \\
\hline 2 & Jenis kelamin & & \\
& a. Laki-laki & 3 & 24 \\
& b. Perempuan & 10 & 76 \\
\hline 3 & Lamanya berdagang & & \\
& a. $1-10$ tahun & 1 & 8 \\
& b. $11-20$ tahun & 11 & 84 \\
& c. $>20$ tahun & 1 & 8 \\
\hline 4 & Tingkat pendidikan & & \\
& a. SMP & 1 & 8 \\
& b. SMA & 12 & 92 \\
c. Perguruan tinggi & 0 & 0 \\
\hline
\end{tabular}

Berdasarkan Tabel 1 dapat dilihat aspek-aspek karakteristik tersebut menunjukkan bahwa:

1. Golongan usia pedagang makanan: tidak ada pedagang makanan yang berusia di bawah 24 tahun, 24-54 tahun berjumlah 12 orang, dan 1 orang yang berusia di atas atau sama dengan 55 tahun, yaitu berumur 60 tahun. Umur mempengaruhi pembentukan sikap dan perilaku seseorang, semakin bertambah umur diharapkan makin banyak pengalaman dan pengetahuan, serta kesadaran melakukan tindakan higiene dan sanitasi.

2. Jenis kelamin digunakan untuk mengetahui perbandingan antara pedagang laki-laki dan perempuan. Berikut hasil penelitian yang berkaitan dengan jenis kelamin pedagang makanan jajanan di pasar malam Sindu: pedagang laki-laki berjumlah 3 orang dan perempuan berjumlah 10 orang. Dominasi pedagang perempuan tersebut menunjukkan bahwa perempuan memiliki kelebihan dalam mengolah 
makanan, dengan demikian melakukan tindakan higiene sanitasi lebih sering dibandingkan laki-laki.

3. Lamanya berdagang sebagian besar telah melakukannya dalam kurun waktu 11-20 tahun. Berdasarkan hal tersebut dapat disimpulkan bahwa, hubungan pengetahuan dan pengalaman kerja bermakna setelah mencapai 1 (satu) tahun atau lebih, seperti dalam penelitian Agustina, dkk (2010). Semakin lama seseoranga melakukan pekerjaan akan mempengaruhi ketrampilannya, dalam hal ini terkait higiene dan sanitasi.

4. Tingkat pendidikan terakhir: SMP berjumlah 1 orang, SMA berjumlah 12 orang, Sebagian besar pendidikan terakhir pedagang makanan jajanan di pasar malam Sindu adalah SMA. Pada tingkat pendidikan ini, pedagang makanan memiliki keterbatasan pemahaman terhadap higiene dan sanitasi. Namun, dengan lamanya berdagang yang mempengaruhi pengalaman dan pengetahuan, sehingga tidak sulit untuk memahami tindakan higiene dan sanitasi.

\section{B. Higiene Perorangan Pedagang Makanan}

Higiene perorangan dianggap penting karena bisa menghentikan penyebaran bakteri dari pelayan yang membawa makanan sampai makanan yang telah disiapkan. Setiap orang bisa membawa bakteri yang merusak badan yang terdapat pada: kulit-rambut, mulut-tenggorokanhidung, kuku yang kotor, seragam, dan menjadi sumber terkontaminasinya makanan.

Khususnya penjamah makanan yang bertugas pada pengolahan makanan bisa menjadi sumber kontaminasi, dengan menularkan penyakit sebagai bawaannya. Namun sebagai pembawa penyakit atau racun, seringkali penjamah makanan tidak menyadari adanya gejala penyakit di dalam tubuhnya yang bisa mengakibatkan kontaminasi terhadap makanan. 
Penelitian Syahrizal (2017) juga mengemukakan bahwa pemeliharaan higiene perorangan diperlukan untuk kenyamanan individu, keamanan, dan kebersihan.

Kesehatan penjamah makanan berperan penting dalam sanitasi makanan. Ketika penjamah makanan terkena penyakit atau keracunan, maka potensi sebagai sumber kontaminasi menjadi meningkat. Oleh karenanya, penjamah yang sakit atau terinfeksi tidak boleh melakukan atau menangani kontak langsung pada makanan atau peralatan yang digunakan dalam pengolahan, persiapan dan penyajian makanan. Kelalaian akan hal ini akan mengakibatkan makanan terkontaminasi dan kemudian menjadi penyakit bagi yang memakannya.

Penjamah makanan harus konsisten menjalankan aturan higiene perorangan, seperti:

1. Mencegah kontaminasi silang dengan melaksanakan tindakan higiene (mencuci tangan, tidak melakukan kontak langsung dengan makanan).

2. Pastikan kebersihan dan sanitasi terhadap peralatan makanan yang digunakan.

3. Jangan menumpuk piring ketika menyajikan makanan kepada tamu.

4. Pastikan tempat makan bersih dan dilap secara regular.

Higiene perorangan pedagang makanan jajanan Bali di pasar malam Sindu berdasarkan hasil penelitian disajikan pada Tabel 2.

Tabel 2

Distribusi Pedagang Makanan Berdasarkan Higiene Perorangan Di Pasar Malam Sindu, Sanur, Bali

\begin{tabular}{|c|c|c|c|}
\hline No & Kategori & Jumlah & $\%$ \\
\hline 1 & Baik & 3 & 23 \\
\hline 2 & Tidak Baik & 10 & 76 \\
\hline & Total & 13 & 100 \\
\hline
\end{tabular}

Berdasarkan Tabel 2 dapat dilihat bahwa higiene perorangan menunjukkan: 
1. Pedagang makanan dengan higiene perorangan baik berjumlah 3 orang.

2. Pedagang makanan dengan higiene perorangan tidak baik berjumlah 10 orang.

Penjamah makanan yang melakukan higiene perorangan dengan baik, terlihat pada beberapa tindakan berikut:

1. Memakai celemek saat membuat nasi goreng yang dipesan wisatawan asing.

2. Mengambil makanan yang disajikan dengan menggunakan alat penjepit.

3. Mencuci tangan setiap kali akan bersentuhan dengan makanan.

4. Tidak menggaruk anggota badan saat mengolah makanan.

5. Tidak menyentuh makanan secara langsung.

Penjamah makanan yang melakukan higiene perorangan dengan tidak baik, terlihat pada beberapa tindakan berikut:

1. Tidak menggunakan celemek saat melakukan pengolahan makanan, sehingga baju tampak kotor.

2. Tidak menggunakan alat penjepit untuk mengambil makanan, melainkan menggunakan tangan.

3. Merapihkan makanan yang terjatuh dari piring dengan menggunakan tangan.

4. Tidak mencuci tangan sesudah memegang uang.

5. Memegang hidung yang mungkin gatal, saat mempersiapkan makanan yang akan disajikan. 


\section{Sanitasi Peralatan}

Peralatan yang digunakan untuk menjual makanan adalah salah satu hal yang harus diperhatikan dalam higiene sanitasi makanan, karena peralatan sangat berpengaruh pada kebersihan makanan. Hal ini disampaikan dalam penelitian oleh Setyawanti dan Andayani (2015).

Pencucian dan perawatan terhadap peralatan makanan dimaksudkan untuk mencegah bakteri berkembang biak dan menyebar pada makanan. Bakteri akan mudah berkembang biak bila berada di lingkungan yang kotor.

Kontaminasi makanan dapat terjadi setiap saat, salah satunya dari peralatan makanan yang digunakan tidak memenuhi syarat kesehatan, seperti dalam penelitian Syahrizal (2017). Selanjutnya, diungkakan bahwa pencucian peralatan sangat penting diketahui secara mendasar, dengan pencucian secara baik akan menghasilkan peralatan yang bersih.

Menghindari pencemaran bakteri terhadap peralatan makan dengan cara melakukan pencucian minimal dalam 2 bak, yaitu:

1. Bak 1 untuk mencuci peralatan dengan larutan deterjen.

2. Bak 2 untuk membilas dengan air bersih.

Hasil pencucian peralatan maksimal diperoleh dengan memakai air hangat.

Adapun pencucian peralatan masak dan peranti saji dilakukan terpisah, tidak digabung karena tingkat kotorannya berbeda. Peralatan masak lebih banyak mengandung kotoran dibandingkan peranti saji. Di samping itu peralatan dapur sebagian besar terbuat dari metal, stainless steel, aluminium yang membutuhkan proses pencucian dan perawatan yang khusus. Sedangkan peranti saji dari keramik, gelas yang lebih mudah pecah, kecenderungan tidak memerlukan pencucian yang rumit, melainkan kehati-hatian, sehingga tidak memecahkan barang-barang tersebut. 
Sanitasi peralatan yang digunakan pedagang makanan jajanan Bali di pasar malam Sindu, berdasarkan hasil penelitian disajikan pada Tabel 3.

\section{Tabel 3}

\begin{tabular}{|c|c|c|c|}
\hline Distribusi Pe & $\begin{array}{l}\text { gang Makanaı } \\
\text { i Pasar Malan }\end{array}$ & $\begin{array}{l}\text { arkan Sa } \\
\text { anur, B }\end{array}$ & tasi \\
\hline No & Kategori & Jumlah & $\%$ \\
\hline 1 & Baik & 6 & 46 \\
\hline 2 & Tidak Baik & 7 & 54 \\
\hline & Total & 13 & 100 \\
\hline
\end{tabular}

Berdasarkan Tabel 3 dapat dilihat bahwa sanitasi peralatan menunjukkan:

1. Pedagang makanan dengan sanitasi peralatan yang baik berjumlah 6 orang

2. Pedagang makanan dengan sanitasi peralatan yang tidak baik berjumlah 7 orang.

Pedagang makanan yang melakukan sanitasi peralatan dengan baik, terlihat pada beberapa hal berikut:

1. Terdapat 2 bak untuk mencuci peralatan.

2. Peralatan dicuci menggunakan sabun dan dibilas dengan air bersih.

3. Peralatan dikeringkan dengan lap bersih.

4. Tidak menggunakan peralatan kembali, yang dirancang untuk satu kali penggunaan.

5. Peralatan disimpan di tempat khusus yang bersih.

Pedagang makanan yang tidak melakukan sanitasi peralatan dengan baik, terlihat pada beberapa hal berikut:

1. Tempat pencucian peralatan hanya 1 bak dengan air yang sudah tidak jernih.

2. Peralatan makan diletakkan di dekat pencucian dengan tidak rapih, hal ini memungkinkan terjadinya kontaminasi. 
3. Peralatan sekali pakai diletakkan berserakan, tidak rapih dan memungkinkan terkontaminasi.

4. Membersihkan peralatan dengan serbet yang tidak bersih dan kumal.

\section{Sanitasi Penyajian Makanan}

Bagian terpenting pada proses penyajian adalah mencakup beberapa hal di bawah ini:

1. Makanan jajanan yang disajikan harus dengan tempat/alat perlengkapan yang bersih dan aman bagi kesehatan.

2. Makanan jajanan yang dijajakan harus dalam keadaan terbungkus dan atau tertutup.

3. Pembungkus yang digunakan dan atau tutup makanan jajanan harus dalam keadaan bersih dan tidak mencemari makanan.

4. Pembungkus makanan dilarang ditiup.

5. Makanan jajanan yang diangkut, harus dalam keadaan tertutup atau terbungkus dan dalam wadah yang bersih.

6. Makanan jajanan yang diangkut harus dalam wadah yang terpisah dengan bahan mentah sehingga terlindung dari pencemaran.

7. Makanan jajanan yang siap disajikan dan telah lebih dari 6 (enam) jam apabila masih dalam keadaan baik, harus diolah kembali sebelum disajikan.

Menjajakan makanan dalam keadaan terbuka dapat meningkatkan risiko tercemarnya makanan oleh lingkungan, baik melalui udara, debu, asap kendaraan, bahkan serangga. Makanan yang dijajakan di pinggir jalan akan sangat mudah terpapar debu dan asap kendaraan yang berterbangan. Hal ini diungkapkan dalam penelitian Agustina, dkk (2010).

Sanitasi penyajian makanan jajanan Bali di pasar malam Sindu, berdasarkan hasil penelitian disajikan pada Tabel 4. 
Tabel 4

Distribusi Pedagang Makanan Berdasarkan Sanitasi Penyajian Di Pasar Malam Sindu, Sanur, Bali

\begin{tabular}{|c|c|c|c|}
\hline No & Kategori & Jumlah & $\%$ \\
\hline 1 & Baik & 7 & 54 \\
\hline 2 & Tidak Baik & 6 & 46 \\
\hline & Total & 13 & 100 \\
\hline
\end{tabular}

Berdasarkan Tabel 4 dapat dilihat bahwa sanitasi penyajian menunjukkan:

1. Pedagang makanan dengan sanitasi penyajian makanan yang baik berjumlah 7 orang.

2. Pedagang makanan dengan sanitasi penyajian makanan yang tidak baik berjumlah 6 orang.

Pedagang makanan yang melakukan sanitasi penyajian makanan terlihat pada beberapa hal berikut:

1. Makanan yang disajikan menggunakan peralatan yang bersih.

2. Penyajian makanan panas dilakukan dalam keadaan panas.

3. Tempat saus sambel ditutup.

4. Penyajian makanan dipisahkan berdasarkan jenisnya, misalnya ikan, sayur, daging.

5. Menyajikan makanan dengan peralatan yang bersih.

Pedagang makanan yang tidak melakukan sanitasi penyajian makanan dengan baik terlihat pada beberapa hal berikut:

1. Penyajian makanan jajanan diletakkan di tempat terbuka menggunakan baki tanpa ditutup.

2. Peralatan makanan piring ada yang cacat.

3. Penyimpanan makanan di dalam rak kaca, tidak diberikan penutup sehingga lalat masuk dan hinggap di makanan.

4. Menyentuh langsung makanan yang akan dihidangkan, tidak menggunakan alat. 


\section{Simpulan dan Saran}

\section{A. Simpulan}

Para pedagang makanan jajanan tradisional Bali di pasar malam Sindu, secara umum paham terhadap pentingnya melakukan tindakan higiene dan sanitasi untuk keamanan makanan. Namun demikian, tidak semua pedagang menerapkan hal tersebut saat memberikan layanan. Berdasarkan observasi langsung, terhadap penerapan higiene dan sanitasi oleh para pedagang makanan jajanan, berikut ini penjelasannya.

1. Tindakan higiene dan sanitasi yang diterapkan oleh beberapa pedagang makanan jajanan tradisional Bali di pasar malam Sindu adalah:

a. Memakai celemek saat mengolah makanan.

b. Mengambil makanan dengan alat penjepit.

c. Mencuci tangan.

d. Terdapat 2 bak pencucian dan pembilasan.

e. Tidak menggunakan peralatan kembali yang dirancang untuk sekali pakai.

f. Penyajian untuk makanan panas tetap dalam keadaan panas.

g. Memisahkan makanan ikan, sayur, daging dalam wadah yang berbeda.

h. Menyajikan makanan dengan peralatan yang bersih.

2. Tindakan-tindakan higiene dan sanitasi yang tidak diterapkan oleh beberapa pedagang makanan jajanan tradisional Bali di pasar malam Sindu:

a. Tidak menggunakan celemek, sehingga baju kotor dan tidak higiene.

b. Penyajian makanan jajanan diletakkan di tempat terbuka menggunakan baki tanpa ditutup. 
c. Menyentuh makanan dengan tangan yang tidak dicuci terlebih dahulu.

d. Tempat pencucian peralatan hanya satu, tidak ada tempat pembilasan.

e. Makanan jajanan diletakkan di baki tidak ditutup.

f. Peralatan makanan ada yang cacat, retak.

g. Makanan di rak tidak ditutup.

h. Menyentuh makanan secara langsung.

\section{B. Saran}

Saran-saran yang penting diperhatikan sebagai alternatif untuk menarik wisatawan asing menikmati makanan jajajan Bali di pasar malam Sindu adalah:

1. Pihak berwenang, memberikan pemahaman, penyuluhan, pelatihan tentang higiene sanitasi kepada pedagang makanan jajanan Bali secara regular, serta melakukan pengawasan terhadap pelaksanaan higiene dan sanitasi.

2. Pedagang makanan hendaknya melakukan tindakan-tindakan higiene dan sanitasi untuk menarik wisatawan, serta meningkatkan penjualan makanan.

\section{Daftar Pustaka}

Agustina, Febria. Dkk. 2010. Higiene Dan Sanitasi Pada Pedagang Makanan Jajajan Tradisional Di Lingkungan Sekolah Dasar Di Kelurahan Demang Lebar Daun Palembang. Jurnal Ilmu Kesehatan Masyarakat, Vol. 1, No. 01 Maret 2010.

Bartono PH. 2008. Pengantar Pengolahan Makanan. Jakarta: PT Perca.

Keputusan Menteri Kesehatan Republik Indonesia Nomor 942/MENKES/SK/ VII/2003 Tentang Pedoman Persyaratan Hygiene Sanitasi Makanan Jajanan. Lumanauw, Nelsye. 2018. Pengembangan Makanan Tradisional Bali Pada Pasar Malam Sindu, Sanur, Bali. Jurnal Ilmiah Hospitality Management, Volume 9 No. 1. Bali: Sekolah Tinggi Pariwisata Bali Internasional.

Malhotra, Naresh K. 2009. Riset Pemasaran Pendekatan Terapan, Jilid 1. Jakarta: PT. Index. 
Prastowo, Ichwan. 2017. Hotel Hygiene dan Sanitation. Yogyakarta: Dee Publish.

Putra, R. Masri Sareb. 2017. Prosiding International Congress I Dayak Culture. Banten: An1Mage.

Setyawanti, Okta dan Sri Wahyu Andayani. 2015. Higiene Dan Sanitasi Jajan Pasar Di Pasar Kotagede Yogyakarta. Jurnal Keluarga Vol 1, No 2 September 2015.

Simanjuntak, Bungaran Antonius, dkk. 2015. Sejarah Pariwisata. Jakarta: Yayasan Pustaka Obor Indonesia.

Syahrizal. 2017. Hygiene Sanitasi Penjamah Makanan Terhadap Kandungan Escherichia Coli Di Peralatan Makanan Pada Warung Makan (Hygiene sanitation food handlers to the content of Escherichia coli on cutler at food stalls). Jurnal AcTion: Aceh Nutrition Journal, November 2017: 2(2): 132136.

Undang Undang tentang Pangan RI No. 18 Tahun 2012, tentang Keamanan, Mutu \& Gizi Pangan.

Widyati, Retno dan Yuliarsih. 2002. Higiene \& Sanitasi Umum dan Perhotelan. Jakarta: PT Grashindo. 
Nelsye Lumanauw

44 JOURNEY Volume 1 Nomor 2 Juni 2019 